\title{
13. Panel Discussion: Diverse perspectives on the evidence
}

\section{Larissa Behrendt, Tom Calma, Geoff Scott, (with introductory remarks by Jon Altman)}

\section{Jon Altman}

The aim of this panel discussion is to get some diverse perspectives on the evidence. To do that we have arranged a panel of three people who will evaluate the evidence on socioeconomic outcomes for Indigenous Australians as articulated in the first day of this conference and then look at those with respect to their diverse professional and academic experiences. We thought it would be very useful at the end of Day 1 of this conference to have some discussions that would tease out how and, indeed, if statistical collections can add substantially to the debate on Indigenous policy. We are sure these statistics can do that, and I am sure the panel would agree with that. One of the main questions to be addressed is how large scale statistical collections can be improved to collect more accurate information about Indigenous circumstances so that policy can be better informed to address Indigenous disadvantage and need. What I will do is introduce my distinguished panel in the order that they will speak, and invite them to speak for up to 15 minutes on what they have heard today.

The three panelists are: Larissa Behrendt, Professor of Law and Indigenous Studies and Director of the Jumbunna Indigenous House of Learning, University of Technology, Sydney; Geoff Scott, who has had a long and distinguished career, and is currently holding two positions: Chief Operating Officer of the New South Wales Aboriginal Land Council in Sydney, and Distinguished Professor in Public Policy Research at University of Technology in Sydney; and Tom Calma, the Aboriginal and Torres Strait Islander Social Justice Commissioner, and Acting Race Discrimination Commissioner with HREOC.

\section{Larissa Behrendt}

I would like to begin by acknowledging country and Matilda House's welcome this morning and paying my respects to the Ngunnawal people, and to the many Aboriginal nations who are represented at this conference among the audience and participants.

I've been asked to make a few reflective comments, and I do that as someone who has a legal background, rather than being a statistician or a policy maker.

In the law reform work we do at Ngiya, where we are primarily trained as lawyers, we are very reliant on statistical analysis as a part of the methodology 
that we sometimes engage in. But more often we rely on people like Don Weatherburn and the ABS, the Productivity Commission and the NATSISS to be able to have a stronger base from which to articulate what we hear anecdotally. This base data allows us to counterpoint the rhetoric and ideologies that we see influencing the legal and policy agendas we are working on within our research unit.

One of the things Jon's speech reminded me of this morning is that there are many key roles that are being lost with the abolition of ATSIC and he touched on one when he mentioned its very vital role in collecting data that was independent of government. It seems to me that the ability to provide a form of independent advice from government has been lost in many of the roles that ATSIC used to play. So, for example, we saw it play a similar role in relation to the issue of native title. We saw it play a similar role in relation to the way it analysed Australia's performance under our key human rights organisations. And we saw it in the way it focused in this era of reconciliation on a more developmental rights framework, including agendas such as a treaty. These viewpoints were in many instances much more reflective of Indigenous people's perspectives on policy issues than of the Australian Government's, and often stood in stark contrast or opposition to federal government policy. So, with the eradication of that national representative structure, there has been an increasing feeling amongst Indigenous communities and families of incredible disempowerment and I guess also too we are often hearing comments about how quickly these changes have come along and they are saying 'I didn't realise it was a new era because the changes have happened so rapidly'. With the fast pace that ATSIC was abolished and a new system was put in place, many Indigenous people felt left out of that change because indeed they were not consulted about it or included and they felt left behind by these enormous changes happening within the sector.

Despite the rhetoric of government that the abolition of ATSIC structures has meant government can now directly engage with Aboriginal and Torres Strait Islander communities, the questions that we've heard asked most often is one that Jon Altman raised this morning, and that is: who is it that government is actually engaging with? Many commentators have noted there is a real inconsistency with policy on the one hand that it is interested in greater interaction and negotiation with communities through things like SRAs but on the other hand seeks to destroy a regional representative model that would have facilitated that negotiation.

It is interesting to note that the areas that seem to have done the best in navigating SRAs are areas like Murdi Paaki in New South Wales where there was a very strong ATSIC regional council and their ability to navigate the changes has very much been led by the very strong regional council work that was being 
done there. We need to remember that there is evidence, both here (much of it done by CAEPR) and overseas (particularly in the mainland of the United States and Canada) that shows that socioeconomic outcomes are best improved when Indigenous people are included in priority setting, policy development and program delivery. It is not simply an ideology of self-determination that shows that: it has been actually proven by research. This evidence of the importance of having Indigenous people involved in the administration, development and planning of policy has been overlooked in the rush to enter SRAs.

The underlying issue that can be gleaned from Jon's observations this morning is that much of the data that would assist communities in making informed choices about entering into those sorts of agreements - what areas they might want to cover, what additional services they might need and seek, what sorts of priorities they might want to focus on - has not been provided to allow Aboriginal people to enter into these agreements in an informed way. Nor is there a framework for assessing those agreements to monitor their effectiveness or their fairness.

I would also note that one of the things we have noticed from our research work is that, in addition to the sorts of enquiries we get from community people about what SRAs are, how do we figure out if we want to be involved in them, and what sorts of things should we be looking at? We are particularly interested in the number of people who work within various State and Territory government departments who seem to be asking the same sort of question about the process, the substance and the evaluation of SRAs.

One of the key problems is that the SRAs have been led by the ideology of mutual obligation and other aspects of Indigenous policy have been driven by an ideology of mainstreaming. Ideologically-driven policy is not always in line with research-based policy - in fact, it rarely is - but the latter has a better chance of addressing socioeconomic disadvantage than the former.

I want to conclude by flagging three ways in which we can improve these outcomes and use the sort of statistical analysis that we have been talking about today.

Firstly, the ATSIC legislation provided for a regional planning process. With the abolition of ATSIC and the regional councils, we have lost a mechanism by which we can engage in that sort of analysis and planning within each of the regions. I think it's really important that we re-establish that as a framework for working through any negotiation process that is intended by the SRAs. It is true to say that the promise of the regional planning processes that were articulated in the ATSIC legislation were never actually met. But I think it provides a framework for the groundwork you would need to do to actually start effectively engaging communities and targeting priorities in different areas. The example I would use of a really good regional mapping process is the 
Fitzgerald Report in Cape York - the Cape York Violence Study — which, even though it was initiated by concerns about levels of violence and substance abuse, did a mapping exercise that was really thorough in terms of looking at issues of governance and the involvement of State and federal agencies in the area. It's an excellent example of how you could map out a regional area. So I think you need to go back and do that planning process that was foreshadowed but seems to have been lost in the impetus to try and come up with large numbers of SRAs without doing that sort of groundwork beforehand.

The second thing I would flag is the need to rethink the way in which SRAs are approached. There is no doubt that the idea of negotiating with Indigenous communities is an important one. I have already mentioned that there is a great deal of evidence to show that you need that sort of involvement to ensure programs are going to be successful. In theory, the notion of SRAs should actually be able to provide some way of engaging meaningfully with Aboriginal communities. I think one of the real concerns is that that promise has been lost in the way that SRAs have been approached in practice. I think we need to rethink the way the process for engaging in SRAs is thought out and make it much more transparent. This process needs to include issues like who actually has the mandate and who is making the agreement. We need to ensure there are mechanisms in place to monitor the content, to ensure they are not breaching basic human rights or that there is no bargaining for essential services. Also, there should only be a commitment made to provide something as part of the exchange, particularly by governments, if there is a capacity for them to do so. You will all be familiar with the stories of kids turning up to school as part of their agreement, only to find out there were not enough teachers or classrooms. There also needs to be more attention given to the issue that was raised in this morning's presentation about that real need to come up with a framework for monitoring and evaluating those agreements to ensure that the outcomes are actually beneficial to Indigenous people, and they are making some kind of impact.

The third thing I would raise is the way in which we need to empower communities to work alongside the statistical research that we do. There is a need to increase the number of Indigenous people in the public service. One of the really unfortunate side effects of the abolition of ATSIC and the move from ATSIS into the Office of Indigenous Policy Coordination (OIPC) was the loss of numbers of Indigenous people working within the public service, particularly across the Senior Executive Service. We have actually seen a large drop in the number of Indigenous people who were transferred from OIPC into other government departments but found that this was a very different environment than the one they signed on for, so they have quietly left. I think that has been a real step back for us, because it has been an important development that more and more of our people have been working within the policy area. It's never an 
easy choice to make as an Indigenous person, but I really respect people who have done that. It is a real shame that we have lost so much of that capacity under the new arrangements. Ensuring those numbers increase in the future will be another big challenge.

\section{Geoff Scott}

I would like to start by acknowledging country and the Ngunnawal people on whose land we gather today. I would like to say this forum has been quite useful. I found 70 per cent was quite useful, and 30 per cent was completely over my head. But it also raised issues where I should take a lot more interest and also some concerns. But the honesty about the data and its usefulness is very enlightening.

I would like to pick up the first point in Jon Altman's paper this morning: that the central tenants of policy have moved over the last few months. The principles have moved. I'm sorry, there is no principle, it's about mainstreaming, mutual responsibility and whole of government. That's a positive move that was pursued by ATSIC for a number of years but was not pursued by government. What I think it does acknowledge with government is that they have continued to fail in service delivery. For the amount of money going in and the effort involved, the results have not been what were intended and there are reasons for that. The national commitment to improve services to Aboriginal and Torres Strait Islander people was put in place in 1992 and confirmed again by the Council of Australian Governments (COAG) in 1994, and then they came up with the COAG Agreement in 2000.

What was missing in all of those issues was the authority of central government: it was not there. It was an impediment to service delivery, an impediment to research, it was an impediment to access to data. That is one thing I think you will be facing in your studies as well. That is there now, but it only came about when ATSIC was removed from the environment. The accountability provisions of government have changed as well. The accountability provisions now are not measuring performance as disbursement, but accountability as being accounting. They were the measures imposed on ATSIC.

They've moved now to accounting for activity, and for some outcome performance, which is a positive development. It's a shame it has taken so long to come out. The point that should be made here, about the way ATSIC went about its business, is that the critical insider is not tolerated in this government. It is not tolerated in today's society. If you criticise government, you will suffer. I think most people here today are aware of that. Today it's about controlling the media. There are positives in the environment. If we make our comments about the history of what has happened, then greater minds will look at that and make their assessments in the future when the venom goes out of the debate. 
The shift to a greater focus on communities and regions is not a negative development. But it needs a fundamental policy framework to underpin it. It needs a policy framework underpinned by research and analysis. I do not know how you identify what a community is. In a lot of Australia, it is a very nebulous concept. Who are you talking to, who do you have an agreement with, who makes up your community, and who's got authority? And I'm sure the people in OIPC and the Indigenous Coordination Centres (ICCs) are grappling with that now.

It's also about identifying the issues, and needs and concerns, but also both the symptoms and causes of those. Identifying the existing service mechanisms, identifying the baseline data, and then what milestones you are looking for. What are the impacts, and how we measure the outcomes? That's why, in terms of today, the 2002 NATSISS survey (and its outcomes) is just one aspect of the whole package that could be backed up by the case studies, by the longitudinal studies. But it is a very useful mechanism. The challenge we face is to meet this emerging requirement. The Productivity Commission work was mentioned a couple of times this morning. What I think that report and the Commonwealth Grants Commission confirms is the dearth of data availability, of access to data and of analysis.

One massive problem I see in the current policy framework is that we develop all these frameworks of what the indicators were. They are sitting there up at the national level.

On the ground we've got SRAs. There's no link, and that should be a worry to us all. We have lots of activity. That's not to say SRAs are bad. They are potentially a useful mechanism, but by themselves they are quite dangerous. In saying that, I would like to make the point that outcomes and impacts is a function of a number of policy initiatives, and the resources applied to those initiatives. It's about incentives and penalties, and service accessibility and strategies. It's not about one program. Some of the data presented this morning actually brought that out. I was in the States recently. Listening to the TV, advertising for a drug, they say take drug A and it will fix B (your condition), but by the way, here are the side effects, and they read off a long list. An interesting analogy, I would suggest.

But on those issues this is the problem of the way in which policy frameworks are implemented. We have no way of measuring the intended or unintended consequences of a policy initiative. Some of the work this conference is doing in trying to identify some of those relationships is extremely important. It is a body of work that has not been done. This is exacerbated by the silent mentality of government agencies, at both Commonwealth and State levels. It is a challenge for the new environment. They are trying to work in practice but on the ground it is not working very well. I do not think you can ask a Minister to give away 
his power over money that he is responsible to government for. Nor will a Secretary give away decision making power over something that his Minister will hold him accountable for. So you have to change the very tenets of government policy to give this process a chance to work. The other point I would like to make here is that we have to try to understand in this policy context the difference between development and intervention. In this country, most of the policy initiatives you see are interventionist. The SRAs are interventionist. The work in the Cape York report focused on interventions, and mentioned the difference between development and intervention, but did not take it further.

Another important point that was raised this morning was about social capital, about human capital. Intervention to date has focused on services and infrastructure. You need to build a sustainable social capital framework to underpin that. In Australia when you mention intervention it is a dirty word, but overseas you can do it. We need to build the necessary framework for that.

Boyd Hunter raised the issue this morning about poverty. The whole poverty debate and how narrow and immature it is in this country. It's not just income. It's about powerlessness and exclusion. It's about capacity. Without taking on poverty and all those related aspects of exclusion, one will not succeed.

One point that was raised this morning was mobility. It's very important in today's emerging policy environment, especially the policy arising from the reports issued by the CGC (2001). When the Commission was doing their work, they tried to do an absolute needs-based measurement and they were told no, you're not allowed, we want a relative one. It's all about an ideology of moving specific funding for Indigenous affairs to the north, to the more remote areas, and then requiring government line agencies to fill the gap left behind by the other programs. So it's very important from that point of view. Coming out of that presentation this morning is a number of factors looking at what mobility was. It's a function of security and social capital. If someone's not scared to move, they will do it. If they are, they will stay at home. And that's no different to anyone else. That's human nature. Everyone likes the status quo. They will not move unless they see a positive in moving. It's those issues that are brought out of that point for me.

On what the drivers and levers are, have you seen recently there is a move on having home ownership on community lands? There is a move on promoting scholarships to help people to leave their communities for education. This concept of orbits has been put up now and bandied around. We have transient employment issues where the great new initiative for Aboriginal people is fruit picking, as suggested in a CIS study. Send people down south at a cost of about $\$ 12000$ to earn $\$ 4000$. I do not know where the economies come in there, but it made a good story. 
Another issue is child mortality which was very interesting this morning as well. I have put it that this study is going to be very useful for someone who is a rational policy maker. There is data being presented here that is quite useful in explaining the relationship between the different factors. Coming out of the child mortality debate this morning was the relationship between a stable and safe and secure home environment, both from an economic and a health point of view. The discussion about social stresses and the primacy of the home environment were equally important. We need to identify what those positives were.

Another point there is that policy makers drive demand, mobility being one example. We all must be aware of what use the information produced will be put to. There must be an implicit acknowledgment there that the economic growth and development required to sustain people in remote areas is just not there. It's fanciful to keep saying that it is. Government put the people on the excisions and the reserves and now it's come to the reality that it's going to cost a lot of resources to maintain that, and the economies are not there.

There was a point this morning about the CDEP scheme. Be very careful about confusing the vagaries of CDEP. The ABS classifies a CDEP participant as being employed. If CDEP representatives were here they could tell you that from their perspective, CDEP participants are unemployed.

The dual focus on development versus intervention is critical. I keep making that point because I think it is very important. One issue I am very critical of, and have been for some time, has been government's service delivery-it's all from a project mantra. Projects are great because the financier controls the project, the timing, the outcome, and also controls the credibility and the sustainability of the organisations that get the money. I work with an organisation at the moment and they spend most of their time chasing next year's money, not doing what they are supposed to do because of the uncertainty that is derived from that. In terms of capacity, they're the sorts of things to look at. We need to look at what these initiatives are doing. We are pitting remote versus non-remote and we must be careful about those issues. It's a real issue emerging between Aboriginal communities at the moment, between north and south. It's going on behind the scenes, but the debate is going on. And no-one wants to do that, no-one in the south wants to deny someone in the north for the relative needs they have, because they do have those needs, but with a finite amount of resources that debate will happen. And it causes dissension.

If we are going to have sustainable development, we need to focus on people-centred money, or 'hot money'. International development discussions talk about hot and cold money. Cold money is focused on infrastructure and services. Hot money is focused on people. It's about increasing the capacity of people to sustain those services and carry on when the government leaves, or 
when the project leaves. That debate is not happening here at the moment. It takes a lot of time to heat that money up and make it hot. Just moving on to the large scale collections we are focused on here, and the aggregate data. You have to be careful with those. In terms of methodology we do not lose sight of the indicator of predictors of change, both positive and negative. A bad experience can inform as much as a good experience can at times. You cannot lose sight of that. You cannot lose sight of the detail itself. Usefulness can be the causality of aggregation.

From a policy point of view, the first question I ask when I receive a statistical report or a research report from a research forum is, does it confirm my gut feeling? Does it confirm the observations? If it does, great. If it does not, it is important go through the data and try to talk to someone about it. Try to get a feel for policy makers who have 101 things to focus on, most of which in today's environment is what the Minister wants, not what the public servants want. They work for the government, not for the client.

The 2002 NATSISS survey cannot be used in isolation. It needs to be coupled with case studies and with longitudinal studies, and that is what we are missing at the moment. They should inform each other. The real problem here is issue identification within the extant constraints, be they financial, political or other constraints between governments.

I would like to see a study on the transaction costs between governments in Indigenous affairs. You would find it's enormous. Something I'm sure no Senate would want to embark on, but it is important.

The role of a research forum like this, noting that putting data up that embarrasses people or puts you on the spot will cause you pain, is to keep the bastards honest. It's also about remaining objective. Another measure is utility: What policy has changed or been affected by these studies? I think in terms of looking at the usefulness for what you are doing in the future. If policy-makers are ignoring it, then we can have good press releases and we can have good conferences, but not a lot changes. But it's still important to keep doing the work, keep the flame alive.

The issue for Aboriginal people today is a day-to-day survival issue. Some of the studies will show that in reality when working at a community level and working with people, it is a day-to-day survival issue. We cannot lose sight of that, and the impact of government policy on that.

\section{Tom Calma}

Thank you, Geoff. Let me also acknowledge all the Ngunnawal peoples of Canberra today and thank them for allowing us to hold this conference on their lands. 
I have found the conference so far very, very useful. A lot of information has been given. I would like to commend CAEPR for being able to pull it together. Firstly, it allows all presenters to provide scrutiny of their peers, and to be challenged about their analysis of the statistics. The objective of influencing the ABS about how they might construct the next NATSISS is critically important. It is good to note that there are a number of bureaucrats here, although some more senior bureaucrats would have been welcome. Many of the people here are in the chain but they are not the ones who are making the decisions, and are not the ones able to influence the decision makers. So we need to look at ways to be able to engage the most senior of bureaucrats, and the most senior of politicians who make the policy or direct the way policy goes, to participate in forums, or at least be informed by forums of this nature.

I would like to give a plug for a seminar I will be conducting in collaboration with the Productivity Commission and Reconciliation Australia next month. It's looking at the Productivity Commission's report Overcoming Indigenous Disadvantage. There will be a number of Indigenous speakers in a similar forum to this, looking at it a bit more from a policy perspective and also the engagement of many Indigenous people who are able to give their perspective on various elements of the report. I would welcome you there if you have the opportunity.

From my perspective, both as the Aboriginal and Torres Strait Islander Social Justice Commissioner and previously in bureaucracy, I have found NATSISS to be a useful tool, but not as useful as other reports that are produced, such as the Health and Welfare Survey, CHINS, and the various reports the Productivity Commission puts out. What is most important, and what I find of most value to many of us who are not statisticians or involved in high level research, are the reports from academics from all institutions who are able to do that analysis and are able to provide us with data that we can understand and get a handle on.

While saying that, while the data is useful, it is only one element of trying to address the situation of Indigenous peoples. It was interesting to hear one of the speakers this morning talk about housing. It is often through practical reconciliation trying to look at equity between Indigenous and non-Indigenous people that issues can be addressed. We look at housing as a typical example, where Indigenous people are so far behind in home ownership, either outright ownership or in the purchase of homes. But let's take it back a step-it's only 40 years since we were formally recognised and able to get wages, so we have a lot of catch-up to do. It was only 40 years ago that we got a whole lot of rights that we previously did not have. So, to be able to compare the Indigenous to the non-Indigenous population, and where we are at, is sometimes misleading.

It is also equally a problem when you look at statistics. For the policy developers here, the analysis of the statistics is an analysis of people and their lives and most often they are in fact, never acceptable or show positive improvement. But 
to be able to develop policies to address situations and to expect overnight outcomes is unrealistic. So we have to look at longitudinal studies. Geoff mentioned, and I fully support the idea of longitudinal studies and specific case studies, and I will talk about that a bit more. But just listening to some of the speakers this morning, it became evident that we need to do more to coordinate some of the numerous surveys that are undertaken nationally by different institutions, because from the user's end of it, it is difficult to know which is the best or most accurate interpretation of the situation of Indigenous Australians.

The danger is people can pick up just one report and focus on one element of information and expect to develop a policy. But while that is not good practice, it is nowhere near as dangerous as a Minister or Prime Minister visiting a community and somebody putting up their hand and saying, 'I would like to own a house', so we get a new policy on home ownership. It's these knee jerk reactions that I think are dangerous for Indigenous people and our advancement, because what is really required from our perspective is to be fully and meaningfully engaged in any process that involves us, and any policies that are being developed that affect us. And that engagement has to be done from the perspective of knowing precisely what the engagement is going to mean and how it is being influenced. Because, to have any sustainable outcome we need to have full engagement, and Larissa and Geoff both talked about this.

I mentioned the longitudinal surveys and case studies which are important. For example, the report on Wadeye recently done by John Taylor was very good, and one would think that should have been embraced by the government as saying that these are the facts, let's get on and deal with them. But it was not necessarily embraced at all - it actually had a negative effect.

We are still waiting on the lessons learnt from the COAG trials. When we consider that the whole of the new arrangements for Indigenous affairs are predicated on the lessons we have learnt from the COAG trials, one would suspect we should have had some document outlining what those good lessons were. But we have not. Unless we get data that is useful and able to be translated into policy that becomes useful, we do not achieve very much. We have sad situations. Palm Island, for example: we all know what's happened on Palm Island, and the investment that has gone into Palm Island, Mutitjulu, the AP Lands, you can go all over the country. Who gets the blame at the end of the day for the lack of advancement? Indigenous people, it's all our fault. When really it's government policy and we are only reacting and surviving through that.

I thought I would ask my Indigenous colleagues here to raise their hand if you have ever participated in a NATSISS survey. We've got two, because I did too. That was the one last year. It was interesting, and this is a bit of a reflection on how accurate are the statistics when we have two out of 30 Indigenous people 
here who have participated. I heard one in 30 nationally earlier, so maybe that's a good stat.

When we look at Canberra, for example, my situation was interesting. At the time of completing the survey, I had just returned from overseas and this is interesting because mobility statistics is one of the lines of questioning and it indicates that Indigenous peoples are mobile. I must say the NATSISS survey is complicated. The interviewer said it will only take you 20 or 30 minutes, but $1 \frac{1}{2}$ hours later I was still going, and still trying to work it out. The questions are complicated and they're multi-dimensional. You think you are going down one track, and then it changes.

It was interesting because for statistical purposes I had just come back from Vietnam, I'd been in temporary accommodation, and by the time I was surveyed I had moved back into my house. I had lived in three locations in the past 12 months. I was fully mobile. So those statistics are sometimes questionable. I think just listening to what was indicated earlier today, there needs to be some consistency in questions asked of people living in urban areas versus those in rural remote areas. But because the form is complicated, the real challenge is making sure that the surveyors are skilled to be able to undertake the surveys in a way that is going to be able to elicit the right kinds of answers. What is also important is to make sure there is consistency across all the surveyors because if there is not, the outcomes will be different because the ways you present those questions will determine how the survey may be influenced. One question it would be interesting to know the answer to, and I don't know whether it's asked, is whether anyone has been surveyed previously. The question is whether the survey is hitting the same people each time, or different people.

In relation to the training of the surveyors, I think its going to be important. I had a question in relation to what I think is a good initiative: the six Indigenous ABS officers who are placed around the country. From my perspective, they would have a good role as an ongoing promotion tool out into the communities and in bureaucracies to be able to get people to understand what the surveys are about. Why that is important, and some may remember this, is that in the late 70s/early 80s we had the Electoral Education Officers, who were itinerant officers, who floated around the country and the Australian Electoral Commission engaged them to promote the electoral system. These people could take on a similar role. There is also a role to start educating the community, and I will touch on this more in my session tomorrow on rights. But it is in relation to prior and informed consent. Do not wait until a month or so before the survey to tell people that you are going to do it. Use it as a process to educate the community well and truly before the event.

Where to in the future? I would like to propose something radical like a triennial Indigenous survey. You might say every six years is bad enough, what are you 
going to do every three years? I think there is value in it because it is very important to have information that will influence policy makers. I think OIPC has a phenomenal challenge because their job is now to be able to coordinate and inform Indigenous policy. From what basis, I might ask? From the 2002 NATSISS statistics? We do not have any other benchmarks, as they are the benchmarks. A lot has happened in the last couple of years. The economy has turned around. It has gone up, it has gone down. For example, we are seeing many more mining interests engaging people out in communities. If we are going to get some benchmarks, if we are going to determine if there has been an improvement in the life and circumstances of Aboriginal people, we need to have those benchmarks established.

I am sure the ABS is saying it is too hard. One of the solutions may very well be to have a survey that targets remote communities. We have between 1200 and 1300 discrete Indigenous communities. A majority of them are serviced through CDEP. It could very easily be arranged, through the whole-of-government arrangement with DEWR, to engage some of the CEDP workers, train them up, and have them conduct the survey. By the time the second survey comes around in six years time, firstly we will have a benchmark. Larissa and Geoff both talked about governments now saying that a lot of the effort needs to go out into remote communities where the need is greatest - though I'd argue against that. That's one way of doing it, through CDEP, to push it through.

I wanted to mention briefly the issue of needs: needs-based priority or allocation of funding. It is often a misnomer to say 'where the need is greatest'. Statistically it may very well be greatest for those who are most impoverished, those without employment. For policy makers, they also need to consider Aboriginal people, be they in the city or remote areas, who have some capacity to be able to advance. Education is probably the best area to look at. Instead of directing all the programs down to those with the lowest educational capacity, some of our programs need to be directed towards Indigenous people who have some capacity, who are coping. They may be in a gifted program. Those people who are coping, who are in gifted programs, in my view suffer because there is no support for them, it all goes down the other way. Indigenous people have a double whammy. We are expected to be able to find full employment, buy a house - and educate our kids. The moment we start to get anywhere near a decent salary we are penalised because we suddenly lose access to tuition support, study allowance for students and so forth. Often the statistics are distorted because there are many Indigenous kids now who are leaving specific programs like ABSTUDY and going on to Youth Allowance because it is easier to get and you do not have to go through half the hassle you have to do to get Indigenous programs. 


\section{QUESTIONS}

\section{Boyd Hunter}

I have a comment for Larissa, supporting your last comment about declining public sector employment. I have been working on a conference presentation for the Conference of Economists next month, where I will have the pleasure of sitting opposite Helen Hughes. I was looking at the statistics for the change in public sector employment without CDEP over time. There has been a very strong decrease for Indigenous employment for the whole of Australia. It has actually fallen as CDEP employment has increased. There seems to be a greater fall for Indigenous public sector employment than for the rest of Australia. The Public Service Commission's State of the Service report more or less confirms this, with Indigenous employment in the Australian public sector declining consistently since 1999.

\section{Murray Geddes}

You indicated there is a major mismatch between the scale of data and information collections and the current focus of policy on the local level - local level variable area agreements and so on. Would you like to explore how we might build that in? For example, a capacity building, evaluation and data component. Though I guess you would expect that those components, if that what was built in, would need to be managed other than by the program managers, who have a vested interest in not getting uncomfortable information. Would you like to comment on some of the explorations, even if you are really not trying to reconstruct ATSIC regional structures in the process.

\section{Geoff Scott}

I do not have a direct answer for you. The process employed when ATSIC was in place, was the Office of Evaluation of Audit. That was a useful process because the people had a very positive focus. I have not seen any sort of measure of evaluation of the COAG trials or SRAs today, and that is a worry. It is one of the things that we are trying to give advice to communities on. At this stage, the dearth of information about SRAs is one of the major inhibitors. I do not think even the Human Rights Commission can get access to the data

\section{Jon Altman}

I might just make a comment on behalf of John Taylor. The work he is doing in Wadeye involves working with local data collectors. I think there really is opportunity and obligation on researchers who work in Indigenous communities to facilitate the enhancement of the capacity of local people through local organisations to collect data. It is a cliché to say information is power, but if you are going to start getting into SRAs you certainly want three sources of 
information. You want the community information, the government information, and the independent information, I think that in reviewing any SRAs or COAG trials you need to have that tripartite approach. The issue I think we have all been negligent about, and Geoff has mentioned this frequently in the past and again today, is that we have not really built community capacity for data collection for development purposes. But some places have done it, as Larissa mentioned. Some regions have that capacity and they succeed, so we have the evidence that it works - what we need to do is invest in that capacity. That can sit alongside national surveys, regional surveys, and other data collection exercises but certainly that capacity is needed at the community level. Having said all that, defining communities and regions is difficult. I was quite comfortable with 60 regions once upon a time, then it became 36 regions. Now regions are going to become increasing flexible, and that is going to very hard in relation to historical data. How do these regions or communities fit in with census or ABS geography?

\section{Paul Howarth}

A couple of observations, and then a question. The first observation is picking up on something Tom said. The more intensive the condition, the more frequent the observation. If you think about someone who is in intensive care, a lot of time and effort and resources go into keeping track, as regularly as possible, of the situation they are in. There is no more intense policy than the Indigenous situation at the moment and I think it justifies the resources.

Secondly, I am thinking about the two data sets that have been the focus today: the 2002 NATSISS and census information. One of the issues that we come across is the lack of a nationally consistent approach to the way in which national data is used and interpreted. What is a household from an Indigenous perspective? What is a community? Making sure that these definitions are less nebulous would go a long way to help passing on the information to government departments, particularly making sure the data is reasonably objective, which is one of the things we struggle with often.

My third point relates to the methodology of the two main surveys discussed today. One is around the concept that we apply those surveys in the individual household levels. One of the things that we have thought about with some of our policy work in the past is the idea of a survey that can be administered to understand communities from the point of view of isolating and accounting factors of capacity, governance and service provision in a nationally consistent way. I suppose that CHINS does this to a certain degree, and there are aspects of data collection that do this too. We often find it's an important aspect of trying to work out what are the variables, what are the influences. 
While geography is one powerful variable, we find that community capacity is also a very powerful variable. I am wondering whether or not there is an idea of consensus around the need for that type of collection to happen as well.

\section{Geoff Scott}

Through the Australian Collaboration Foundation, New South Wales Aboriginal Land Council plus other groups around Australia, including Reconciliation Australia, we are looking at that very question.

There has been a predominant assumption that governance is the problem. If you take this view, I think you have jumped two steps down the track instead of trying to identify the issue. Very often it depends what you define as governance, it depends who you spoke to last. At the moment, the capacity of communities is a major determining factor.

Stability of community structures and their organisation is an important issue, particularly whether their structures are community-based in reality. I am currently trying to investigate these issues in terms of identifying organisations around the country that have been succeeding, explore the reasons why they are successful, and look at what governance actually means. Governance is a much bandied cliché at the moment which just serves to confuse people and does not contribute to the debate at all.

Part of the methodology there is how you define success, and from whose perspective - whether it is from the perspective of the financier of the organisation, the client base, and of the peers, and all those issues as well. We are trying to get some definitions that can be useful and comparable. Comparability of data is one of the major problems. The Productivity Commission reports in previous years had a table which identified the comparative data across the country in the different program areas but I notice that it was not in this report.

\section{Peter Radoll}

I have a question for Tom in regard to education. You hinted that education may be one key to advancing our communities and you touched on a great subject of what do you do with gifted Aboriginal children. That gave me time to reflect on my time at the Indigenous Education Consultative Body here in the ACT, where we did have some very gifted children. These children are considered gifted from the mainstream perspective. Not only do these kids have to outperform their own cohort or the other Aboriginal and Torres Strait Islander kids in the ACT, but they also have to outperform all the kids in the ACT. To get funding for those children who are probably the most potential leaders at the national level at least, to get funding to assist those, well...you cannot. There is no way to actually get those children any sort of a leg-up, or for the families 
as well. For a child who finds it difficult to read in kindergarten, you can get a whole lot of resources. How do we address that?

\section{Tom Calma}

That is the point of my comment. The policy makers need to influence the Minister to consider investing in that level because we will never get the number of Indigenous people getting through to tertiary studies, getting into the professional level, if we do not start helping those who are capable to go through as well. There still needs to be effort put into those who have the greatest need. But there also needs to be some consideration given to those who have the capacity if we are going to facilitate the process of advancement of Indigenous Australians. Part of the problem is that, even though there are mechanisms in place to coordinate activities, agencies are still operating very independently. There is still a lot of room to be able to work a lot more collegially in approaching these issues.

\section{Larissa Behrendt}

I would like to add one thing to that. I think that question goes to the heart of what is really difficult about policy in relation to education, what is really difficult about policy in relation to improving socioeconomic statistics in Indigenous communities, and what is difficult about Indigenous governance.

When we do find instances where community organisations succeed, one of the key factors that seems to be replicated in each of the case studies is the fact that those community organisations have an individual in them who drives that organisation. Where we see regional councils being successful compared to other regional councils, it is usually because of the calibre of the regional council chair, so this success is driven by an individual. It is one of the real difficulties in terms of a holistic approach to improving the socioeconomic conditions of Indigenous communities.

We tear our hair out trying to come up with a formula as to how to improve the socioeconomic conditions of Indigenous families. What we see, particularly through our connections with the university sector, is that when you have an individual person graduate with a tertiary degree, there's an Indigenous family that is never going to live in poverty again. They've got the capacity to earn an income and they introduce a culture of learning into their family which will be disseminated through the generations.

It's really hard to make policies to say that every time we set up a community organisation or structure or a governance system we need to have an individual of exceptional capacity who can drive it. It does go to show that one of the really big challenges is actually focusing on the ability to be able to develop that capacity in the individuals where they arise. That is why the leadership programs 
that we see building up across the country are really a key mechanism in doing that, particularly when they have a large outreach into a wide variety of communities. These programs need to bring people in to get the leadership skills they need, as well as the intellectual and emotional support they need, to carry those enormous burdens when they go back into their communities. 